\title{
Cloning and characterization of a TFIIIC2 subunit (TFIIIC $\beta$ ) whose presence correlates with activation of RNA polymerase III-mediated transcription by adenovirus E1A expression and serum factors
}

\author{
Eric Sinn, Zhengxin Wang, Robert Kovelman, ${ }^{1}$ and Robert G. Roeder ${ }^{2}$
}

TFIIIC2 is a general factor essential for transcription of 5S RNA, tRNA, and VA RNA genes by mammalian RNA polymerase III and consists of two forms designated TFIIIC2a and TFIIIC2b. TFIIIC2a and TFIIIC2b share common subunits of $220,102,90$, and $63 \mathrm{kD}$ but differ with respect to transcription activity and the presence of a presumptive 110-kD subunit in the active form (TFIIIC2a). Because both forms can bind the promoter directly, a selective role for the 110-kD subunit in the regulation of RNA polymerase III activity has been suggested. To investigate this possibility, we have cloned and expressed a cDNA encoding the 110-kD subunit (TFIIIC $\beta$ ). Immunoprecipitation studies with anti-TFIIIC $\beta$ antibodies have confirmed that TFIIIC $\beta$ is a bona fide subunit present only in TFIIIC2a, that TFIIIC2a and the general factor TFIIIC1 are associated in unfractionated extracts, and that previously undetected polypeptides (potential TFIIIC1 subunits) can be isolated in association with TFIIIC2a. Previous studies have shown that increases in RNA polymerase III activity during infection of cells by adenovirus (with concomitant E1A expression) or during cell growth at high serum concentration results from an increased activity in the TFIIIC fraction. Studies with antibodies to TFIIIC $\beta$ have shown that this is strongly correlated with a selective increase in the cellular concentration of the TFIIIC $3110-\mathrm{kD}$ subunit and a concomitant rise in the ratio of the active-to-inactive forms of TFIIIC2.

[Key Words: TFIIIC2 subunit; RNA polymerase III; adenovirus EIA; cloning; characterization]

Received October 27, 1994; revised version accepted February 13, 1995.

RNA polymerase III is responsible for the transcription of a number of genes (class III) encoding small nuclear and cytoplasmic RNAs of both cellular and viral origin (for review, see Geiduschek and Tocchini-Valentini 1988; Gabrielsen and Sentenac 1991; Geiduschek and Kassavetis 1992; Hernandez 1993). These genes have been classified broadly on the basis of promoter structure and accessory factor requirements. Both subclass 1 and subclass 2 genes have promoter elements [internal control regions (ICRs)] that are located within transcribed DNA. Subclass 2 genes (encoding tRNA, 7SL, and adenoviral VA RNAs, as well as Alu sequences) have two ICRs (A box and B box) and require factors TFIIIB and TFIIIC in addition to RNA polymerase III for in vitro transcription. Subclass 1 genes (encoding 5S RNAs) have three ICRs (A box, I box, and C box) and require the gene-specific factor TFIIIA in addition to TFIIIB, TFIIIC, and RNA polymerase III. Subclass 3 genes (encoding U6 and 7SK RNAs) have non-transcribed $5^{\prime}$ control ele-

${ }^{1}$ Present address: The Scripps Research Institute, La Jolla, California 92037 USA.

${ }^{2}$ Corresponding author. ments that include a TATA box and a proximal sequence element (PSE) and appear to require the TATA-binding protein (TBP), PSE-binding transcription factor (PTF), TFIIIB, and RNA polymerase III for efficient in vitro transcription.

TFIIIC from mammalian cells (Segall et al. 1980) has been purified and fractionated partially into two activities, TFIIICl and TFIIIC2, which are jointly required for activity (Dean and Berk 1987; Yoshinaga et al. 1987, 1989; Z. Wang and R. Roeder, unpubl.). TFIIIC2 can be isolated in two forms (now designated TFIIIC2a and TFIIIC2b) that bind DNA with equal affinity and show equivalent DNase footprint patterns (Hoeffler et al. 1988; Kovelman and Roeder 1992). However, they can be distinguished by (1) the ability of TFIIIC2a but not TFIIIC $2 b$ to restore RNA polymerase III transcription in a heat-treated nuclear extract, (2) the electrophoretic mobilities (TFIIIC2b > TFIIIC2a) of corresponding DNAprotein complexes, and (3) their subunit complexities; they share common subunits of $220,102,90$, and $63 \mathrm{kD}$ but appear to differ with respect to other polypeptides, most notably the presence of a $110-\mathrm{kD}$ polypeptide unique to TFIIIC2a.

The cellular potential for transcription of class III 
genes by RNA polymerase III in vitro and in vivo has been reported to be enhanced during viral infection by the expression of immediate early proteins of adenovirus (E1A and/or E1B) and pseudorabies virus (PrIE) (Berger and Folk 1985; Gaynor et al. 1985; Hoeffler and Roeder 1985; Yoshinaga et al. 1986; Sollerbrant et al. 1993) and to be suppressed by poliovirus infection (Fradkin et al. 1987). Fractionation of extracts from cells infected with wild-type and E1A-defective adenoviruses has indicated that the E1A-dependent transcription reflects a change in the TFIIIC fraction, variably characterized as an increase in the ratio of TFIIIC2a to TFIIIC2b (Hoeffler and Roeder 1985; Hoeffler et al. 1988) or a net increase in the concentration of TFIIIC2 (Yoshinaga et al. 1986). In related studies it was also found that extracts from cells grown at high serum $(5 \%)$ concentration were more active in transcription by RNA polymerase III than extracts from cells grown at low serum $(0.5 \%)$. The seruminduced change was also localized to the TFIIIC fraction with a similar increase in the ratio of TFIIIC 2 a versus TFIIIC2b (Hoeffler et al. 1988).

To analyze further the regulation of RNA polymerase III-mediated transcription we have cloned and characterized a cDNA encoding the $110-\mathrm{kD}$ subunit of TFIIIC2 and used this to study regulatory modifications and interactions of TFIIIC2.

\section{Results \\ Cloning of TFIIIC $\beta$}

TFIIIC2, purified as described previously (Kovelman and Roeder 1992), was subjected to preparative SDS-PAGE and transferred to an Immobilon-P (Millipore) membrane. The $110-\mathrm{kD}$ subunit of TFIIIC2 was identified and digested with endoproteinase Lys-C. Microsequence analysis of derived peptides yielded sequences of HLLSELEAAPYLPQEEK, DLRRPYEPINSIK, ADLIPYQDSPEGPDHSSA, and EMTSAEASVEMSLPTPLPGFED. Oligonucleotides corresponding to these peptide sequences were synthesized and used to probe a human cDNA library. The largest cDNA in the derived clones contained $1.5 \mathrm{~kb}$ of coding sequence and $1 \mathrm{~kb}$ of $3^{\prime}$ untranslated sequence, but still lacked $\sim 1 \mathrm{~kb}$ of $5^{\prime}$ coding sequence. Although subsequent screening of a number of libraries failed to retrieve more $5^{\prime}$ sequences, the complete $5^{\prime}$ coding sequence was finally obtained using $5^{\prime}$ rapid amplification of cDNA ends (RACE) (see also Materials and methods). The RNA size of TFIIIC $\beta$ was determined using the complete coding cDNA sequence as a probe on an RNA blot. A single band at $4.5 \mathrm{~kb}$ was detected /data not shown).

The complete sequence of the TFIIIC $\beta$ cDNA is shown in Figure 1A. The residues corresponding to those derived from direct protein sequencing are underlined. The cloned TFIIIC $\beta$ cDNA encodes a protein of 911 amino acids with a predicted mass of $100.7 \mathrm{kD}$ and an estimated $\mathrm{pI}$ of 7.0. The protein sequence of TFIIIC $\beta$ was analyzed by computer (GCG, University of Wisconsin, Madison; MacVector, Kodak) and by visual inspection. This re- vealed stretches of basic (residues 90-113, 12/24 basic; residues 141-148, 6/8 basic; Fig. 1A,B) and acidic (residues 237-261, 12/25 acidic; Fig. 1A,B) regions, with a potential basic helix (residues 141-158; Fig. 1A, curved underline) next to a potential acidic helix (residues 244 260; Fig. 1A, curved underline) at the amino terminus. Five putative WD40 repeats (residues 499-513, 571-585, 585-599, 629-643, 852-866; Fig. 1B,C) of potential importance for protein-protein interaction were also found (see Discussion).

A search of the nonredundant data bases with the BLAST network service (Altschul et al. 1990; National Center for Biotechnology Information) was performed to determine possible sequence similarities (protein and DNA) between TFIIIC $\beta$ and other entries. A DNA sequence encoding a protein showing a perfect match $(100 \%)$ to our cloned sequence was found (N. Nomura, N. Miyajima, Y. Kawarabayashi, S. Tabata, unpubl.). This gene was a sequenced cDNA. No other information beside the nucleic acid sequence was found. Outside of this sequence no other significant similarity was found between TFIIIC $\beta$ and other proteins in the data bases (including entries in the protein library as well as translations in all six frames of available DNA sequences).

To determine whether the cloned cDNA contained complete coding sequences for the $110-\mathrm{kDa}$ polypeptide in TFIIIC2, a fragment corresponding to the carboxy-terminal 595 residues was expressed in bacterial, purified to homogeneity, and used to prepare antibodies (see Materials and methods). The putative TFIIIC $\beta$ cDNA was then transcribed and translated in a rabbit reticulocyte lysate and the corresponding product was analyzed, along with a partially purified TFIIIC2 (P11 fraction), by SDS-PAGE. When the corresponding membrane was probed with anti-TFIIIC $\beta$ antibodies a $110-\mathrm{kD}$ band was detected in both the in vitro translated (Fig. 2A, lane 1) and the natural TFIIIC2 (lane 2) fractions. This suggests that the existing clone of TFIIIC $\beta$ contains the complete coding sequence for the presumptive $110-\mathrm{kDa}$ subunit of TFIIIC2a.

The TFIIIC $\beta$ amino acid sequence was compared with sequences from the 220-kD human (L'Etoile et al. 1994) and rat (Lagna et al. 1994) TFIIIC $\alpha$ subunit and with the 95-kD (TFC1: Swanson et al. 1991, Parson and Weil 1992), 131-kD (TFC4: Marck et al. 1993), and 138-kD (TFC3: Lefebvre et al. 1992) subunits of yeast TFIIIC and no significant sequence similarities were found. Consistent with this analysis anti-TFIIIC $\beta$ antibody failed to react on a Western blot with any polypeptide of partially purified yeast TFIIIC (data not shown). The lack of similarity between TFIIIC $\beta$ and yeast TFIIIC subunits is not surprising considering the degree of evolutionary divergence between yeast and vertebrate TFIIIC /see Discussion).

TFIIIC $\beta$ is associated only with the low mobility
transcriptionally active form (TFIIIC2a) of TFIIIC2

As discussed in the introductory section our previous studies have demonstrated two distinct and chromato- 


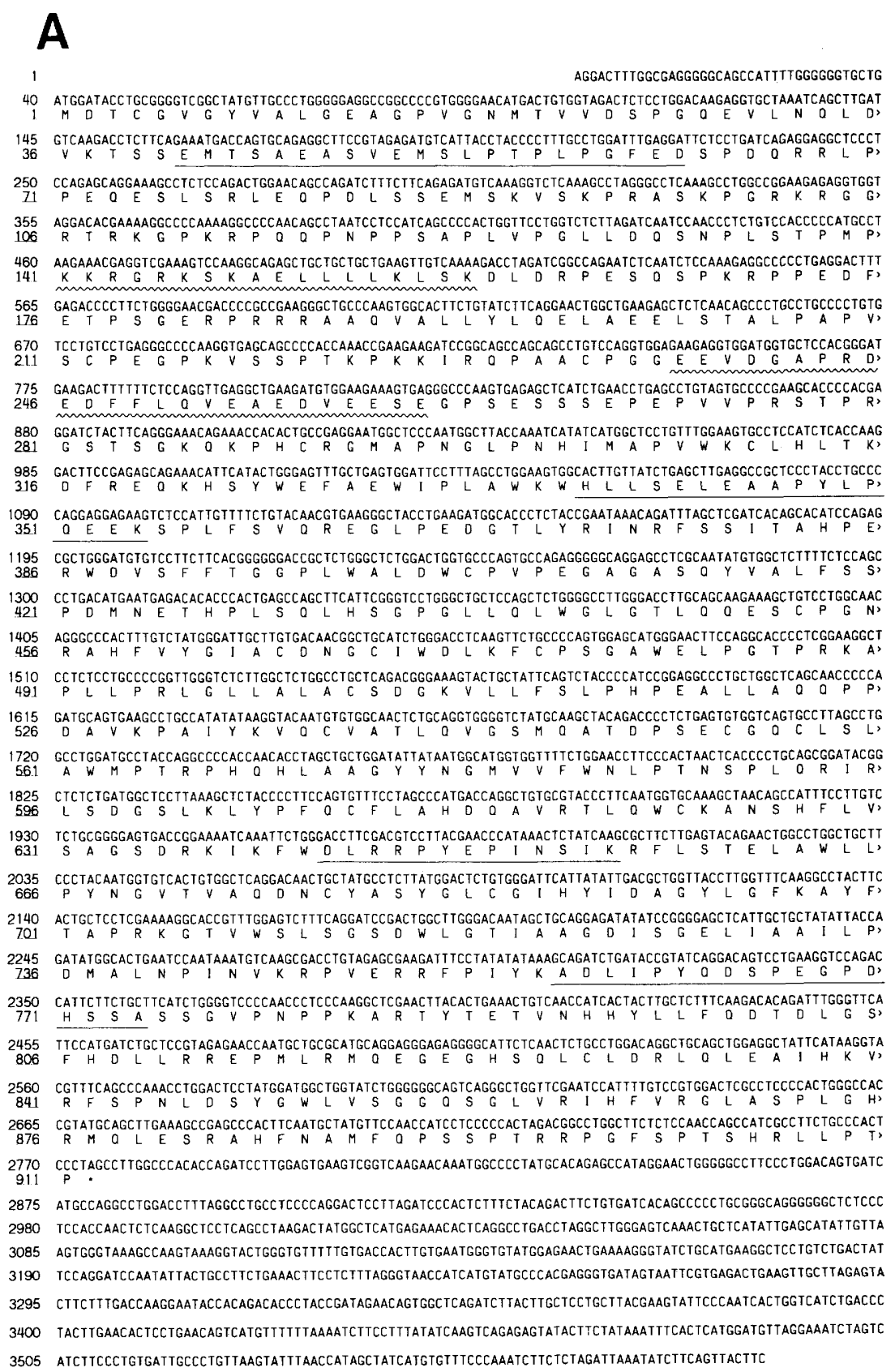

B

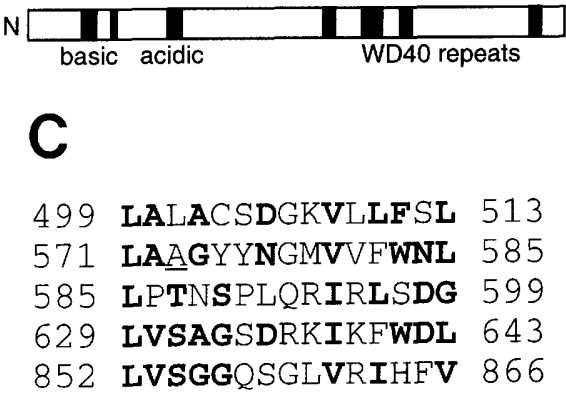

$$
\begin{aligned}
& \text { WD40 } 0 \text { SGGXDXX XIWD号 }
\end{aligned}
$$

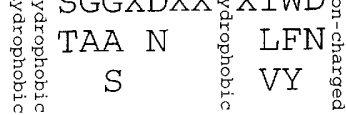

Figure 1. Primary structure of TFIIIC $\beta$. (A) DNA and protein sequence of TFIIIC $\beta$. The numbers at left denote nucleotide sequence, and the underlined numbers denote residue number. The four straight underlined areas indicate regions corresponding to peptide sequences from purified protein. The regions with the wavy underlines are basic helix 141-KKRGRKSKAELLLLKLSK-158 and acidic helix 237-EEVDGAPRDEDFFLQVEAEDVEESE261. (B) Schematic of TFIIIC $\beta$. A schematic of TFIIIC $\beta$ showing the acidic region, basic regions, and the WD40 repeats. $(C)$ Alignment of TFIIIC $\beta$ sequence with WD40 repeats. The top lines are TFIIIC $\beta$ sequences. The bottom line is the consensus sequence of WD40 repeats (van der Voorn and Ploegh 1992). Bold characters represent residues that match the consensus sequence of WD40. Underlined characters represent residues that are in $10 \%$ of all WD40 sequences surveyed (van der Voorn and Ploegh 1992). graphically separable forms of TFIIIC2 in nuclear extracts: one (now designated TFIIIC2a) that forms a promoter complex with a lower electrophoretic mobility and is transcriptionally active in heat-treated nuclear extracts that have preferentially lost TFIIIC activity and a second (now designated TFIIIC2b) that forms a promoter complex with a higher mobility and is transcriptionally inactive in the heat-treated nuclear extract.

Earlier structural studies indicated that these two species contained common polypeptides of $220,102,90$, and $63 \mathrm{kD}$, but differed with respect to the presence of a $110-\mathrm{kD}$ polypeptide in TFIIIC2a, and the apparent presence of $95-$ and $77-\mathrm{kD}$ polypeptides in TFIIIC2b
(Kovelman and Roeder 1992). More recently a modification in the purification protocol has yielded larger amounts of TFIIIC2 and allowed more definitive structural analyses. An analysis of this TFIIIC2 by SDS-PAGE analysis confirmed the presence of $110-\mathrm{kD}$ and $77-\mathrm{kD}$ polypeptides in TFIIIC2a and TFIIIC2b, respectively, but failed to reveal the presence of the $95-\mathrm{kD}$ polypeptide in the latter (Fig. 2C; see also figure legend). To investigate further the presence of the $110-\mathrm{kD}$ polypeptide, and a possible relationship to other polypeptides in the two species, anti-TFIIIC $\beta$ antibodies were used to probe an immunoblot of TFIIIC2a and TFIIIC2b. The analysis in Fig. $2 \mathrm{~B}$ shows the presence of an intact immunoreactive 


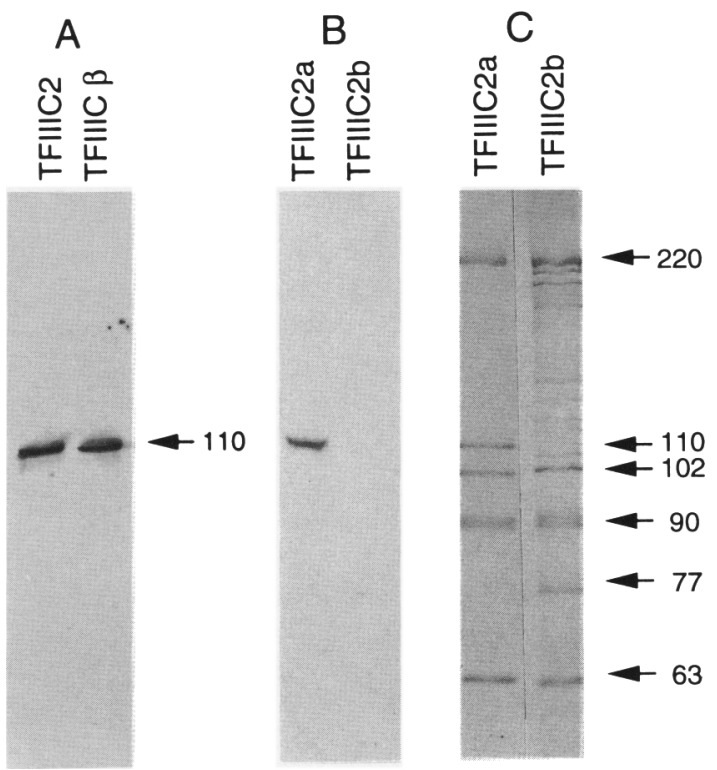

Figure 2. $(A)$ In vitro translation of TFIIIC $\beta$ cDNA. Immunoblot of rabbit reticulocyte lysate translated TFIIIC $\beta$ and purified TFIIIC2 (nuclear extract, P1l 0.6 fraction) probed with antiTFIIIC $\beta$ antibody. The bands detected have a migration rate corresponding to $110 \mathrm{kD} .(B, C)$ Immunoblot of TFIIIC2a and TFIIIC2b. Purified TFIIIC2a and TFIIIC2b fractions (4500-fold) were loaded on $7 \%$ SDS-PAGE and analyzed by immunoblot with anti-TFIIIC $\beta$ antibodies $(B)$ or by silver stain $(C)$. The polypeptides in the $140-$ to $200-\mathrm{kD}$ range in the TFIIIC2 b preparation are not regarded as likely subunits as they do not copurify strictly (during gradient elution) with the TFIIIC $2 \mathrm{~b}$ activity and the other polypeptides. Moreover, the fact that TFIIIC2b has a faster migration rate under gel mobility-shift assays than does TFIIIC2a makes it unlikely that these high molecular mass proteins are part of the TFIIIC2b promoter complex.

110-kD polypeptide in TFIIIC2a but no cross-reacting polypeptide in TFIIIC2b. These results eliminate the possibility that the $77-\mathrm{kD}$ species might represent a modified or derived form of the $110-\mathrm{kD}$ polypeptide. However, they are consistent with the view (substantiated below) that the $110-\mathrm{kD}$ polypeptide is a bona fide subunit that is unique to TFIIIC2a, whereas the $77-\mathrm{kD}$ polypeptide in TFIIIC $2 b$ may be either a contaminant or a reversibly associated component that could play a regulatory role.

Given the proposed role of TFIIIC $\beta$ in effecting changes in the levels of TFIIIC2a in response to certain stimuli, its presence in various subcellular and chromatographic fractions was monitored by immunoblot analysis. TFIIIC $\beta$ was detected only in the nuclear extract-derived $\mathrm{P} 11$ fraction $(0.6 \mathrm{M} \mathrm{KCl}$ eluate $)$ that contains TFIIIC and not in other P11 fractions $(0.1,0.3$, and $1.0 \mathrm{M} \mathrm{KCl}$ eluates). TFIIIC $\beta$ also was not detected in current $\mathrm{S} 100$ and nuclear pellet fractions, consistent with our previous experience that TFIIIC2 activity was undetectable in the same fractions (data not shown). During the further purification of TFIIIC2a through four chromatographic steps (see Material and methods) the
TFIIIC $\beta$ subunit was detected only in fractions that contained TFIIIC2a activity. Thus, the protein (TFIIIC $\beta$ ) encoded by the isolated cDNA copurifies, as expected, only with TFIIIC2a and does not appear to exist in a subcellular compartment independently of TFIIIC2a.

\section{TFIIIC $\beta$ remains bound in a TFIIIC2a-promoter complex}

To gain additional information on the subunit status of TFIIIC $\beta$ and to determine whether it might associate reversibly with the common TFIIIC2 subunits, especially as TFIIIC2a and TFIIIC2b can each form a promoter complex (Hoeffer et al. 1988), it was important to determine whether TFIIIC $\beta$ remains associated with binding of TFIIIC2a to the promoter. Analysis of TFIIIC2a by electrophoretic mobility-shift assay (EMSA) with a VAl promoter fragment (Fig. 3) revealed a characteristic TFIIIC2a-VA1 complex that was dependent on the presence of TFIIIC2a (cf. lane 2 with lane 1) and completely supershifted by anti-TFIIIC $\beta$ antibody (lane 4 ) but not by preimmune serum (lane 3 ). These results indicate that indeed TFIIIC $\beta$ remains associated with TFIIIC2a with promoter recognition, providing strong support for its role as an integral subunit. The interesting possibility that the TFIIIC $\beta$ interaction within TFIIIC2a might be

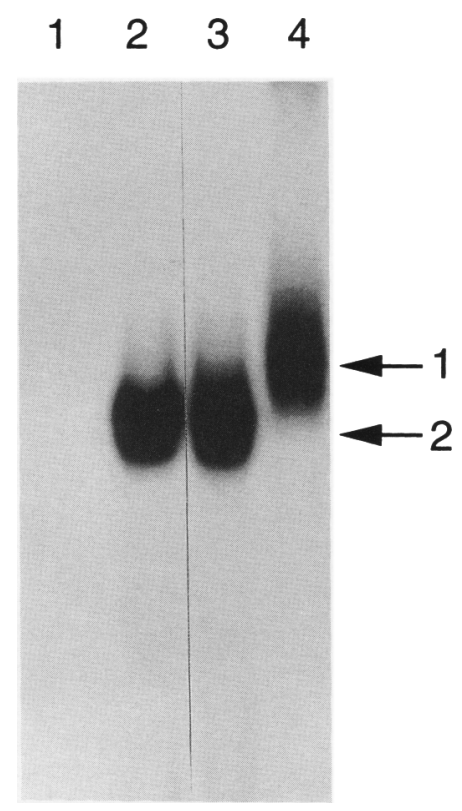

Figure 3. Retardation of TFIIIC2a promoter complexes by antiTFIIIC $\beta$ antibody. EMSA using the labeled VAl promoter of adenovirus. The free probe was run off the gel. (Lane 1) probe alone; (lane 2) probe and TFIIIC2a; (lane 3) probe, TFIIIC2a, and preimmune serum (final antibody concentration, $50 \mu \mathrm{g} / \mathrm{ml}$ ); (lane 4) probe, TFIIIC2a, and anti-TFIIIC $\beta$ antibodies (final antibody concentration, $50 \mu \mathrm{g} / \mathrm{ml}$ ). Arrow 2 points to the TFIIIC2a-promoter complex; arrow 1 points to the TFIIIC2apromoter complex supershifted by anti-TFIIIC $\beta$ antibodies. 


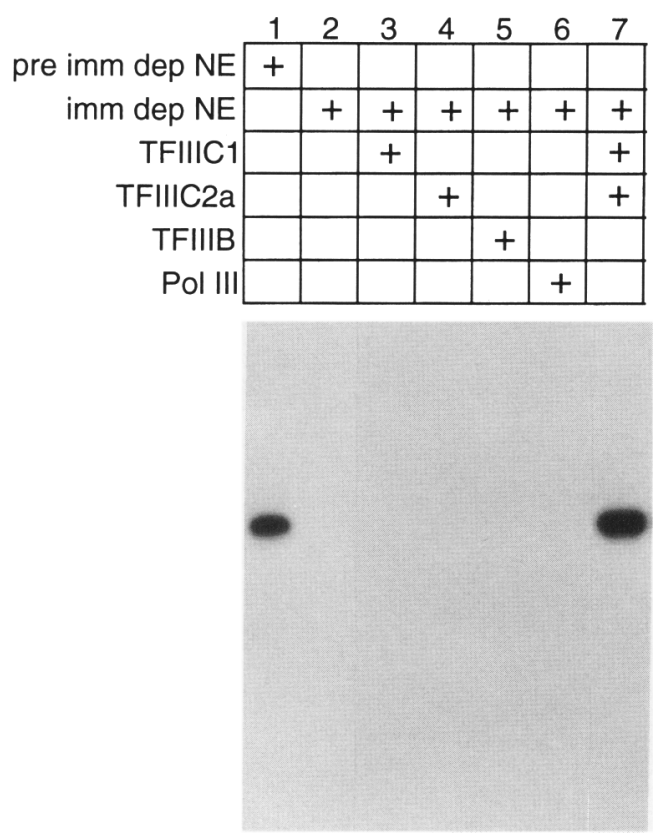

Figure 4. Immunodepletion of nuclear extract using antiTFIIIC $\beta$ antibody. In vitro transcription from the VA1 promoter with preimmune-depleted nuclear extract (lane 1) or with antiTFIIIC $\beta$ antibody-immunodepleted nuclear extract with no addition (lane 2), with TFIIIC1 added (lane 3), with TFIIIC2a added (lane 4), with TFIIIB added (lane 5), with RNA polymerase III added (lane 6), or with TFIIIC1 plus TFIIIC2a (lane 7).

dynamic and only transiently required for transcription initiation remains to be tested.

TFIIIC $\beta$ is involved in transcription by RNA polymerase III and potentially in interactions of TFIIIC2a with TFIIIC1

To determine whether TFIIIC $\beta$ is essential for transcription by RNA polymerase III, antigen-purified antibodies raised against the bacterially expressed carboxy-terminal fragment of TFIIIC $\beta$ were used to immunodeplete a HeLa extract (Fig. 4). As judged by immunoblot this treatment removed $>90 \%$ of TFIIIC $\beta$, whereas preimmune serum had no effect (data not shown). Similarly, whereas the preimmune antibodies had only a minimal $(<20 \%)$ effect on transcription levels (data not shown), anti-TFIIIC $\beta$ antibodies reduced transcription to undetectable levels (lane 2) relative to the high level of transcription observed in extracts treated with preimmune antibodies (lane 1). Independent additions of highly purified TFIIICl, TFIIIC2a, TFIIIB, and RNA polymerase III (lane $3,4,5$, and 6, respectively) to the immunodepleted extract had no effect, with basal transcription remaining undetectable. In contrast, the simultaneous addition of TFIIIC1 and TFIIIC2a restored transcription to levels similar to that observed with the preimmune-treated control (lane 1). Hence, immunodepletion with antibodies against a single unique subunit of TFIIIC2a removes
TFIIIC1 as well as TFIIIC2a activity quantitavely. These results indicate that TFIIIC $\beta$ is an essential component of TFIIIC2a and further suggest that some or all TFIIIC1 components are tightly associated with TFIIIC2a in nuclear extracts.

In an attempt to identify possible TFIIIC2a-associated polypeptides the anti-TFIIIC $\beta$ antiserum was used to immunoprecipitate TFIIIC2a. For this purpose a conventional nuclear extract was adjusted to $300 \mathrm{mM} \mathrm{KCl}$ and applied either to an anti-TFIIIC $\beta$ antibody-protein A column or to a control preimmune antibody-protein A column. The columns were washed with a BC buffer containing $1 \mathrm{M} \mathrm{KCl}$ and eluted with a low $\mathrm{pH}$ buffer. The eluates were immediately adjusted to $\mathrm{pH} 6.8$ and analyzed by SDS-PAGE on either $5 \%$ (Fig. 5 , lanes 1,2 ) or 4-20\% (Fig. 5, lanes 3, 4) acrylamide gels. Along with the previously defined polypeptide bands of $220,110,102$, 90 , and $63 \mathrm{kD}$ (lanes 2,4 ), associated polypeptides of $\sim 58$, 42 , and $33 \mathrm{kD}$ were visible in potentially stoichiometric amounts (lane 4). The 58-, 42-, and 33-kD polypeptides were not detected in purified TFIIIC2a when analyzed on similar gradient gels (data not shown). Although the function of these polypeptides remains to be established, they are candidates for subunits of TFIIIC1.

\section{Effects of adenovirus infection and cellular growth state on the cellular level of TFIIIC $\beta$}

It was reported previously that RNA polymerase III transcription initiation activity is increased both by the viral

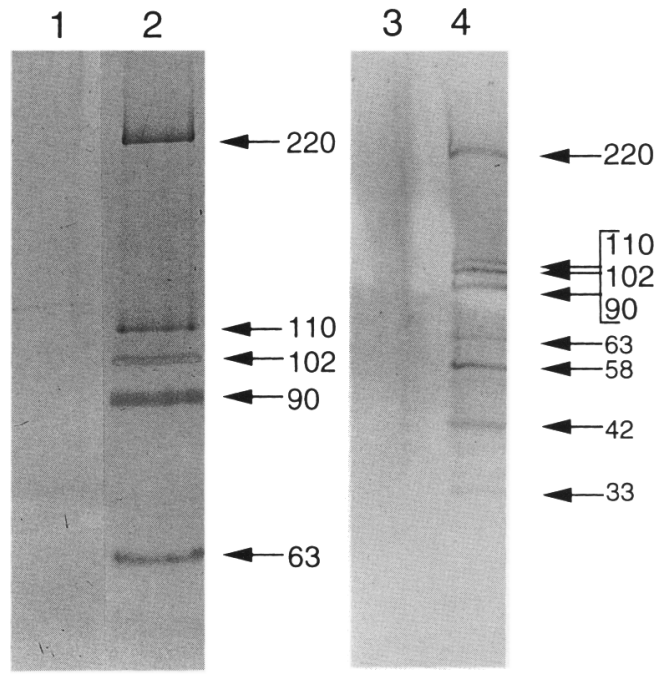

Figure 5. Immunoprecipitation of the TFIIIC2a complex and associated polypeptides using anti-TFIIC $\beta$ antibody. HeLa nuclear extract was incubated for $1 \mathrm{hr}$ with anti-TFIIIC $\beta$ antibody (lanes 2,4 ) or preimmune antibody (lanes 1,3) cross-linked to protein A-Sepharose 4B beads. The beads were washed with BC buffer containing $1 \mathrm{M} \mathrm{KCl}$ and eluted with $0.2 \mathrm{M}$ glycine $(\mathrm{pH} 2.5)$. The eluate was analyzed by SDS-PAGE with $5 \%($ lanes 1,2$)$ and 4-20\% (lanes 3,4) polyacrylamide and stained with silver. The estimated sizes of the subunits are indicated to the right of each panel. 
ElA gene product and by high serum growth conditions (Berger and Folk 1985; Gaynor et al. 1985; Hoeffler and Roeder 1985; Hoeffler et al. 1988). Although the enhanced RNA polymerase III initiation activity was localized to a fraction containing TFIIIC activity, it has not been clear whether the increase in TFIIIC activity resulted from an increase in specific activity (Hoeffler and Roeder 1985; Hoeffler et al. 1988) or from an increase in the amount of TFIIIC (Yoshinaga et al. 1986).

To investigate further the effects of adenovirus infection (including ElA expression) on TFIIIC we infected HeLa cells with wild-type adenovirus (Ad2) and a mutant adenovirus with the E1A gene deleted (d1312). Extracts were produced from cells $6 \mathrm{hr}$ after infection and tested in an in vitro transcription assay with adenovirus VAl and cellular 5S and tRNA genes. Extracts from cells infected with wild-type adenovirus showed a 10-fold higher level of activity than did extracts from cells infected with the ElA-defective adenovirus (Fig. 6A). To determine the basis for the increased activity crude TFIIIC fractions (P11 0.6) from the two extracts were subjected to SDS-PAGE and blotted onto membranes that were probed simultaneously with anti-TFIIIC $\beta$ and anti-TFIIIC $\alpha$ antibodies. Because the 220-kD TFIIIC $\alpha$ subunit was shown previously to be a component of both TFIIIC2a and TFIIIC2b (Kovelman and Roeder 1992), the signal from the corresponding antibody should reflect the total level of TFIIIC2. As shown in Figure 6B, the levels of TFIIIC $\alpha$ were similar for the wild-type $\left(\mathrm{E} 1 \mathrm{~A}^{+}\right)$ and mutant $\left(E 1 A^{-}\right)$cell extracts, suggesting that the E1A-dependent viral gene expression has no effect on the level of total TFIIIC2 in the cell. In contrast, the level of TFIIIC $\beta$, which is only associated with the low mobility form of TFIIIC2, was increased $\sim 10$-fold in the wild-type $\left(\mathrm{E} \mathrm{A}^{+}\right)$extract relative to the mutant $\left(\mathrm{E} \mathrm{A}^{-}\right)$extract. On the basis of these results we conclude that expression of the E1A gene product resulted, directly or indirectly, in an increase in the level of TFIIIC $\beta$ and the corresponding active form of TFIIIC2. Because TFIIIC $\beta$ was not detected in other phosphocellulose fractions (P1 $10.1,0.35$, 1.0 ), nuclear pellet, and S100 fractions, either before or after adenovirus infection (data not shown), it appears that E1A expression results either in an increased rate of synthesis or in the stabilization of TFIIC $\beta$. More recently, preliminary analysis of total cellular RNA levels has indicated a significant effect of ElA expression on the level of TFIIIC $\beta$ mRNA (E. Sinn and R.G. Roeder, unpubl.).

Similar effects also were seen with extracts from cells grown at high $(10 \%)$ versus low $(0.5 \%)$ serum concentrations. Thus, extracts from high serum-grown cells showed 10-fold higher levels of transcription from the VA, 5S, and tRNA genes than did extracts from low serum grown cells (Fig. 6A). Immunoblot analysis using antibodies to TFIIIC $\beta$ and TFIIIC $\alpha$ showed comparable levels of TFIIIC $\alpha$ in both extracts but lower levels of TFIIIC $\beta$ in the low serum cellular extracts (Fig. 6B). These results are consistent with those from the adenovirus infection (E1A expression) experiments and indicate that alterations in specific activity of TFIIIC2 are

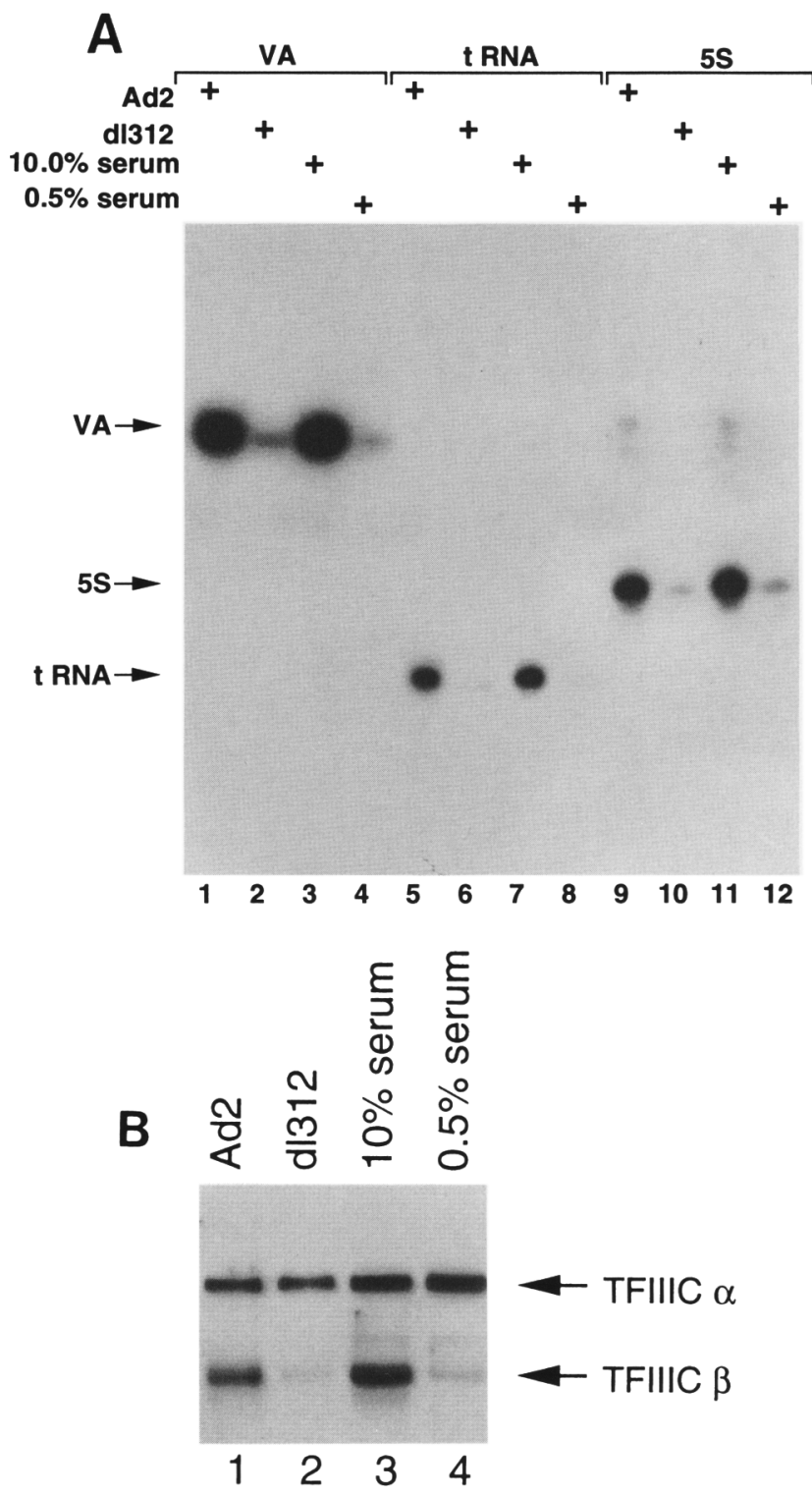

Figure 6. (A) Adenovirus ElA gene product and serum enhance levels of transcription by RNA polymerase III. In vitro transcription using nuclear extracts prepared from cells infected with wild-type adenovirus (Ad2) (lanes 1,5,9), from cells infected with E1A-defective adenovirus (d1312) (lanes 2,6,10), from cells grown in $10 \%$ serum (lanes $3,7,11$ ), and from cells grown in $0.5 \%$ serum (lanes $4,8,12$ ). The same amount of nuclear extract protein was used in each in vitro transcription reaction. $(B)$ TFIIIC $\beta$ and TFIIIC $\alpha$ levels in wild-type virus $\left(E 1 A^{+}\right)$, mutant virus $\left(\mathrm{E} 1 \mathrm{~A}^{-}\right)$, high-serum and low-serum extracts. Immunoblot analysis of the TFIIIC fractions (nuclear extract, P11 0.6) from cells infected with wild-type adenovirus (lane 1) vs. E1A-defective adenovirus (lane 2) or from cells grown in $10 \%$ serum (lane 3) vs. $0.5 \%$ serum (lane 4). TFIIIC fractions correspond to the 0.6 $\mathrm{M} \mathrm{KCl}$ eluates obtained by fractionation of nuclear extracts / the same as those used in $A$ ) on phosphocellulose and were subjected to SDS-PAGE and immunoblot with a mixture of antiTFIIIC $\alpha$ and anti-TFIIIC $\beta$ antibodies.

largely responsible for the difference in TFIIIC2 activity under different growth conditions. 


\section{Discussion}

TFIIIC plays a primary role in promoter recognition and preinitiation complex formation on a subset of genes transcribed by RNA polymerase III and has been implicated in the regulation of these genes by viral immediately early proteins and altered growth conditions (see introductory section). Toward a further analysis of these problems we report the cloning and characterization of a cDNA encoding the second largest subunit (TFIIIC $\beta$ ) of one of the two forms (TFIIIC2a) of the derived TFIIIC2. This cDNA has been used to investigate the primary sequence of TFIIIC $\beta$, regulatory modifications of TFIIIC2 involving TFIIIC $\beta$, and interactions of TFIIIC2 with TFIIIC1.

\section{Cloning and sequence analysis of TFIIIC $\beta$}

Amino acid sequence information from the $110-\mathrm{kD}$ polypeptide present in purified TFIIIC2a was used to obtain a cDNA encoding the corresponding protein. That the encoded protein is a bona fide subunit of TFIIIC2a is indicated by the ability of anti-TFIIIC $\beta$ antibodies (raised against recombinant protein) to inhibit TFIIC function in transcription assays and to supershift TFIIIC2a-VA promoter complexes, thus indicating that TFIIIC $\beta$ is an integral part of the TFIIIC2a complex that initially binds DNA.

The cloned TFIIIC $\beta$ cDNA encodes a protein of 911 amino acids with a predicted molecular mass of 100.7 $\mathrm{kD}$ and an estimated $\mathrm{pI}$ of 7.0. The amino terminus contains short stretches, rich in acidic or basic residues, with the potential to form $\alpha$-helixes. Also present are five regions that conform to the consensus sequence of the conserved B-region of WD40 repeats (for review, see Gilman 1987; van der Voorn and Ploegh 1992). This motif has been found in a variety of proteins implicated in diverse cellular processes that include signal transduction, cell cycle progression, RNA splicing, and both transcriptional repression (TUP1) (Keleher et al. 1992; Tzamarias and Struhl 1994) and transcriptional activation $\left(\mathrm{TAF}_{\mathrm{II}} 80\right.$ ) (Dynlacht et al. 1993; Kokubo et al. 1993). Genetic studies (Keleher et al. 1992) have suggested interactions of WD40 family proteins with proteins containing a tetratricopeptide (TPR) repeat (for review, see Boguski et al. 1990; Goebl and Yanagida 1991), and in the case of TUP1 a direct role for the WD40 repeats in protein-protein interactions has been demonstrated (Tzamarias and Struhl 1994; Komachi et al. 1994). This leads to speculation that the WD40 motifs may be involved in reversible interactions of TFIIIC $\beta$ with other factors such as TFIIICl or TFIIIB. It is interesting in this regard that the $131-\mathrm{kD}$ subunit of yeast TFIIIC contains TPR repeats (Marck et al. 1993), although no WD40 repeats have yet been found in the published sequences of other yeast TFIIIC subunits (E. Sinn, unpubl.).

Given that the five-subunit yeast TFIIIC and human TFIIC (TFIIIC2 plus TFIIIC1) recognize similar promoter sequences (B box and A box) in various class III genes, and that at least some other general transcription components are conserved between yeast and human (Young 1991; Pinto et al. 1992; Hernandez 1993), it was surprising to find that human TFIIIC $\alpha$ and the large subunit of yeast TFIIIC (both of which contact B-box elements) show no significant sequence similarity (Lagna et al. 1994). Following this trend, TFIIIC $\beta$ also shows no significant sequence similarity to any of the three cloned subunits $(138,131$, and $95 \mathrm{kD})$ of yeast TFIIIC. Consistent with these findings, anti-TFIIIC $\beta$ antibodies failed to detect any immunologically related proteins in yeast extracts. Hence, although at least some components (TBP and RNA polymerase subunits) of the RNA polymerase III transcription machinery show substantial sequence conservation between yeast and human (Hernandez 1993; Ittmann et al. 1993) the present and past ( $L^{\prime} \mathrm{E}$ toile et al. 1994; Lagna et al. 1994) observations point either to a functional convergence or to a low sequence conservation in TFIIIC subunits. However, as discussed below, it is likely that human counterparts to some of the yeast TFIIIC components most likely reside in the as yet uncharacterized TFIIICl subunits, and sequences for some of the yeast TFIIIC subunits have not yet been reported.

\section{Subunit structures of variant forms of TFIIIC2}

We reported previously the resolution of two forms of the B box-binding component of TFIIIC, one (now designated TFIIIC2a) that formed a lower mobility promoter complex and showed transcriptional activity in a heattreated nuclear extract and one (now designated TFIIIC2b) that formed a higher mobility promoter complex and failed to show transcriptional activity in the same assay. SDS-PAGE analysis of purified components revealed candidate subunits of $220,110,102,90$, and 63 $\mathrm{kD}$ for TFIIIC2a and candidate subunits of 220, 102, 95, 90,77 , and $63 \mathrm{kD}$ for TFIIIC2b (Kovelman and Roeder 1992). The use of antibodies against TFIIIC $\beta$ has verified that the $110-\mathrm{kD}$ subunit is uniquely present in TFIIIC $2 \mathrm{a}$ and that it is tightly associated in this complex with the 220-, 102-, 90-, and 63-kD polypeptides. On the other hand the $95-\mathrm{kD}$ polypeptide now appears not to be a component of TFIIIC2b because it has not been detected in more recent larger scale and higher yield preparations of TFIIIC2b, either by direct SDS-PAGE analysis (Fig. $2 \mathrm{C}$; Z. Wang and R.G. Roeder, unpubl.) or by SDS-PAGE analysis after immunoprecipitation with anti-TFIIIC $\alpha$ antibodies (L'Etoile et al. 1994; Lagna et al. 1994). In contrast, the $77-\mathrm{kD}$ polypeptide has copurified consistently with TFIIIC2b, although it has not been detected by immunoprecipitation with anti-TFIIIC $\alpha$ antibodies (which might have resulted in its dissociation) (L'Etoile et al. 1994; Lagna et al. 1994). On the basis of these analyses, we conclude that TFIIIC2a contains subunits of $220,110,102,90$, and $63 \mathrm{kD}$, whereas TFIIIC2b differs with respect to the absence of the $110-\mathrm{kD}$ subunit and the possible presence of a substitute $77-\mathrm{kD}$ subunit.

\section{Interactions of TFIIIC2a with TFIIIC1}

Immunoprecipitation studies reported here showed that 
anti-TFIIIC $\beta$ antibodies, but not preimmune serum, can remove quantitatively both TFIIIC2a and TFIIIC1 activities from unfractionated nuclear extracts. These results indicate that at least one of the components that comprise the TFIIICl activity is in stable association with TFIIIC2a (either directly with TFIIIC $\beta$ or with another subunit) and present in an equal or substoichiometric ratio relative to TFIIIC2a. Analysis of the immunoprecipitates revealed polypeptides of 58,42 , and $33 \mathrm{kD}$, in addition to those normally observed in highly purified TFIIIC2a. Consistent with the possibility that these new polypeptides might represent TFIIIC1 subunits, the observed interactions were resistant to washing with $1 \mathrm{M}$ $\mathrm{KCl}$. Although there are reports that TFIIIC2 can interact with human TFIIIA (Lagna et al. 1994) and that human TFIIA may be involved in transcription by RNA polymerase III (Meissner et al. 1993) immunoblots with antibodies to the recombinant $38-\mathrm{kD}$ human TFIIIA /B. Moorefield, E. Sinn, and R. Roeder, unpubl.) and to the 19- and 35-kD subunits of human TFIIA (Delong and Roeder 1993) failed to show cross-reactivity with any of the newly detected polypeptides. In further support of the possibility that these are TFIIICl subunits, they are equivalent in size to a subset of polypeptides present in our most highly purified preparations of TFIIICl ( $\mathrm{Z}$. Wang and R.G. Roeder, unpubl.). The failure to detect these novel polypeptides in previous preparations of chromatographically purified TFIIIC2a (Yoshinaga et al. 1989; Kovelman and Roeder 1992) most likely reflects their dissociation and separation using these purification procedures, and their apparent absence in anti-TFIIIC $\alpha$ immunoprecipitates (L'Etoile et al. 1994; Lagna et al. 1994) may have resulted from their dissociation from TFIIIC2a by the antibodies used. In the present analysis the quantitative removal of TFIIICl activity from nuclear extracts with an antibody (anti-TFIIIC $\beta$ ) specific for TFIIIC2a further suggests that TFIIICl is not associated with the inactive form (TFIIIC2b) of TFIIIC2 and that TFIIIC $\beta$ could play a direct role in stabilizing interactions of TFIIIC2a with TFIIIC1. Alternatively, TFIIIC1 could be so tightly bound to TFIIIC2b that it cannot readily exchange to TFIIIC2a. In the former case any increase in the level of TFIIIC2a (through TFIIIC $\beta$ association with TFIIIC2b) would necessitate a corresponding increased intranuclear concentration of TFIIICl; this could involve recruitment from the cytoplasm, consistent with the presence of high level of TFIIIC1 in the S100 fraction (Z. Wang and R.G. Roeder, unpubl.).

Previous studies have shown that the five-subunit yeast TFIIIC binds to both B and A boxes of promoters, whereas chromatographically purified human TFIIIC2a and TFIIICl bind, respectively, to regions at or near the B box and A box (Yoshinaga et al. 1989; Kovelman and Roeder 1992; Z. Wang and R.G. Roeder, unpubl.). This suggestion of a functional equivalence of human TFIIIC2a plus TFIIICl with yeast TFIIIC is supported by the finding of an apparently strong physical interaction in unfractionated nuclear extract between TFIIICl and TFIIIC2a. It is apparent, however, that there is a greater structural complexity in the human TFIIIC (TFIIIC2 plus
TFIIIC1) than in yeast TFIIIC, unless essential components remain to be elucidated for the latter factor. Furthermore, from the present data one might expect any homology to the A box-binding subunit of yeast TFIIIC (p95; Bartholomew et al. 1990) to be found in human TFIIIC1 and not in TFIIIC2.

\section{Mechanism of transcriptional stimulation by E1A and altered growth conditions}

The adenovirus ElA protein stimulates transcription by RNA polymerases II and III of a number of genes of both cellular and viral origins (for review, see in Berk 1986). In the case of class III genes, TFIIIC was shown to be one of the targets of the ElA-dependent effects on transcription during adenovirus infection (Hoeffler and Roeder 1985). On the basis of template commitment assays, Yoshinaga et al. (1986) reported that this reflected an increased concentration of what current studies indicate must have been TFIIIC2. However, our own studies (using template commitment, mobility-shift, and single round transcription assays) indicated an effect on the specific activity of a preexisting population of TFIIIC2 (Hoeffler and Roeder 1985; Hoeffler et al. 1988; Kovelman and Roeder 1990). Here we have used antibodies to the common TFIIIC2 subunit (TFIIIC $\alpha$ ) and to the TFIIIC2a-specific subunit (TFIIIC $\beta$ ) to verify that the E1A-mediated effect indeed correlates with an increased TFIIIC2 specific activity that results from an increased TFIIIC2a:TFIIIC2b ratio. At present it is not clear whether the effect of E1A on TFIIIC2 is direct or indirect. Related, given the use of wild-type versus E1A-defective viruses in our analysis, the possible involvement of other virus-coded proteins (such as E1B; see Sollerbrant et al. 1993) in conjunction with E1A cannot be excluded.

Analogous to the situation observed during adenovirus infection, the growth of HeLa cells at high serum concentration $(10 \%)$ was shown to enhance markedly the capacity for transcription by RNA polymerase III (Hoeffler et al. 1988; Fig. 4). A similar analysis of extracts from high $(10 \%)$ versus low $(0.5 \%)$ serum grown cells with anti-TFIIIC $\alpha$ and anti-TFIIIC $\beta$ antibodies further established that the effects of serum on TFIIIC2 activity result from an increased TFIIIC2 specific activity, with an increase in the ratio of TFIIIC2a:TFIIIC2b. Thus, the proposed mechanism used by adenovirus to enhance the cellular capacity for transcription by RNA polymerase III appears to be the same as that normally used by the cell during serum-stimulated growth.

\section{Modification of basic transcription factors as a global regulatory mechanism for large classes of genes}

To the extent that TFIIIC2 is required for transcription of class III genes they could be broadly regulated by a regulatory modification that changes the ratio of active/ inactive forms. Although TFIIIC appears to be essential for transcription of most class III genes (including those for tRNA, VA RNA, and 5S RNAl, it has been reported 
not to be involved in the transcription of 7SK and U6 genes in vertebrate cell extracts (Waldschmidt et al. 1991; Lagna et al. 1994) and to be conditionally required for U6 genes in yeast (Brow and Guthrie 1990; Moenne et al. 1990; Burnol et al. 1993). Although the earlier vertebrate studies did not exclude the requirement for a form of TFIIIC2 that does not bind the B box (for review, see Lagna et al. 1994|, more definitive studies with antibodies to TFIIIC $\alpha$ have eliminated a role for TFIIIC2 in 7SK and U6 transcription in cell extracts (Lagna et al. 1994). Thus, effects of TFIIIC2 regulatory modifications might well be restricted to a subset of class III genes. This model of regulation may have relevance to the broad class of genes transcribed by RNA polymerase II, as recent studies indicate that different class II genes may have differential requirements for some general initiation factors (Parvin et al. 1994).

Regarding the actual regulatory mechanism our past and present studies argue for a model involving two different structural forms of the multi-subunit TFIIIC2, an active form (TFIIIC2a) that contains the $110-\mathrm{kD}$ polypeptide and an inactive form (TFIIIC2b) that lacks this polypeptide (but may contain another distinct polypeptide; see above). Although both forms may bind to internal promoter elements of 5S, tRNA, and VA RNA genes, only the active form leads to a productive preinitiation complex (with TFIIICl, TFIIIB, and RNA polymerase III) in nuclear extracts. The ability to remove TFIIICl activity quantitatively from nuclear extracts with a TFIIIC2aspecific antibody suggests that the $110-\mathrm{kD}$ polypeptide may influence directly or indirectly interactions of TFIIIC2 with TFIIIC1, and thus control overall function. Hence, we postulate that TFIIIC $\beta$ (the $110-\mathrm{kD}$ polypeptide) is a central controlling subunit for transcription by RNA polymerase III for TFIIIC2-dependent promoters. This is consistent with the suggestion that TFIIIC $\beta$ is the limiting component in RNA polymerase III-mediated transcription in cellular extracts and that the level of TFIIIC $\beta$ (and TFIIIC2a) can be influenced by growth conditions and by virus infection. At the same time we cannot exclude the possibility that these conditions effect other modifications (e.g., post-translational) that may also affect the assembly or stability of active TFIIIC2a or TFIIIC2a-TFIIIC1 complexes.

\section{Materials and methods \\ Purification and protein sequencing}

For microsequence analysis of TFIIIC $\beta$, TFIIIC 2 a was purified as described previously (Kovelman and Roeder 1992). Microsequence analysis was performed as described (Lagna et al. 1994) and yielded peptide sequences of EMTSAEASVEMSLPTPLPGFED, HLLSELEAAPYLPQEEK, DLRRPYEPINSIK, and ADLIPYQDSPEGPDHSSA. For subsequent studies TFIIIC2a and TFIIIC2b were purified from HeLa nuclear extract as described previously (Kovelman and Roeder 1992) with the following modifications. Heparin-Sepharose $4 \mathrm{~B}$ and DNA cellulose columns were omitted. Fast protein liquid chromotography (FPLC) Mono Q (HR5/5, Pharmacia Biotech) and FPLC Mono S (HR5/5, Pharmacia Biotech) steps were added after the P11 col- umn. Both FPLC columns were $1 \mathrm{ml}$ in size and were eluted with 20-ml gradients $(100-600 \mathrm{~mm} \mathrm{KCl})$ in BC buffer $[20 \mathrm{~mm}$ Tris $(\mathrm{pH} 7.9), 1 \mathrm{~mm}$ EDTA, $0.5 \mathrm{~mm}$ PMSF, $1 \mathrm{~mm}$ DTT, 10\% glycerol].

\section{Cloning of TFIIIC $\beta$}

Oligonucleotide probes corresponding to the partial protein sequences (see text) of TFIIIC $\beta$ were synthesized. Inosine (I) was used in positions of fourfold degeneracy. The oligonucleotides were A, GAICTIGARGCIGCICCITAYCTICCICARGARGARAA; B, CCITATGARCCIATIAAYWSIATIAA; C, GCIGATCTIATICCITAYCARGATWSICCIGARGGICCIGATCA; and D, GARGCITCCGTIGARATGTCCCTICCIACICCICTICCIGGITT. The oligonucleotides were kinase labeled and used in an equal molar mixture to screen $1 \times 10^{6}$ plaques from a BJAB library. Fifteen positive plaques were identified and two of the clones contained sequences encoding a protein that included three of the four partial protein sequences. The $5^{\prime}$ sequences were isolated by $5^{\prime}$ RACE according to the manufacturer instructions $\left(5^{\prime}\right.$ RACE kit, GIBCO/BRL). Primers used were gene specific primer 1, 5'-TGGCTCAGTGGGTGTGTCTCATTC-3'; genespecific primer 2, 5'-GGCCACGCGTCGACTAGTACCCCGTGAAGAAGGACACATC-3'; and anchor primer, 5'-CUACUACUACUAGGCCACGCGTCGACTAGTACGGGIIGGGIIGGGIIG-3'.

\section{Bacterial expression of TFIIIC $\beta$}

A fragment encoding the carboxy-terminal 595 residues of TFIIIC $\beta$ was cloned into the pRSETC bacterial expression vector (Invitrogen) to generate a fusion protein with six histidines at the amino terminus. The resultant plasmid (pHisIIIC317-911) was transformed into BL21-DE3 cells (Novagen) and grown in Luria broth. Expression was induced when $\mathrm{OD}_{600}=0.6$ by the addition of IPTG to $1 \mathrm{~mm}$. At $3 \mathrm{hr}$ after induction the cells were harvested by centrifugation at $2000 \mathrm{~g}$ for $30 \mathrm{~min}$ and resuspended in one-tenth culture volume of guanidinium buffer $[6 \mathrm{M}$ guanidine hydrochloride, $20 \mathrm{~mm}$ sodium phosphate ( $\mathrm{pH} 7.8$ ), $500 \mathrm{~mm} \mathrm{NaCl}$ ]. The extract was sonicated (Branson Sonifier 450) for $3 \mathrm{~min}$ at a setting of 5 at $100 \%$ duty cycle. After centrifugation at $2000 \mathrm{~g}$ for $30 \mathrm{~min}$ the supernatant was saved and the pellet was discarded. Batch binding to NTA-nickel (Novagen) resin (Hemdan et al. 1989; Janknecht et al. 1991) was performed at room temperature at a ratio of $1 \mathrm{ml}$ of resin per liter of culture. NTA-nickel resin was washed with 20 column volumes of denaturing buffer 7.8 [20 mM sodium phosphate (pH 7.8], 500 $\mathrm{mm} \mathrm{NaCl}, 8 \mathrm{M}$ urea], followed by 20 column volumes of denaturing buffer $6.0[20 \mathrm{mM}$ sodium phosphate $(\mathrm{pH} 6.0), 500 \mathrm{mM}$ $\mathrm{NaCl}, 8 \mathrm{M}$ urea], and eluted with 2 column volumes of denaturing elution buffer 4.0 [ $20 \mathrm{~mm}$ sodium phosphate $(\mathrm{pH} 4.0], 500$ $\mathrm{mM} \mathrm{NaCl}, 8 \mathrm{M}$ urea]. The denaturing elution buffer 4.0 eluate was purified by preparative SDS-PAGE. The band corresponding to the expressed protein was excised and electroeluted using standard conditions.

\section{Antibody production and immunoprecipitation}

Antibody production in New Zealand White rabbits and immunoprecipitation were done as described (Harlow and Lane 1988) and briefly summarized here. Three hundred micrograms of bacterially expressed TFIIIC $\beta$ was used in the initial injection and booster injections were made every month with $50 \mu \mathrm{g}$ of protein. Blood was withdrawn 10 days after every antigen boost and antibodies were purified by protein A-Sepharose $4 \mathrm{~B}$ column and antigen-Sepharose $4 \mathrm{~B}$ (Sigma) column using standard pro- 
cedures (Harlow and Lane 1988). The final volume of antibodies was identical to the starting volume but with a protein concentration of $1.2 \mathrm{mg} / \mathrm{ml}$. Purified antibodies were cross-linked directly to protein $\mathrm{A}-$ Sepharose $4 \mathrm{~B}$ resin $(2 \mathrm{mg}$ protein per milliliter of resin) by dimethylpimelimidate (procedure in Harlow and Lane 1988). Samples to be immunoprecipitated were incubated with antibody resin at $4^{\circ} \mathrm{C}$ for $1 \mathrm{hr}$ in a rotator, washed with 100 column volumes of $\mathrm{BCl} 1000$ [20 mM Tris $(\mathrm{pH} 7.9$ ), 20\% glycerol, $0.2 \mathrm{mM}$ EDTA, $1 \mathrm{M} \mathrm{KCl}$ ] and eluted with one column volume of $0.2 \mathrm{M}$ glycine $(\mathrm{pH} 2.5)$. The eluate was neutralized with one-tenth volume $1 \mathrm{M}$ Tris $(\mathrm{pH} 6.8)$, and immediately mixed with SDS-PAGE loading buffer.

For immunodepletion of nuclear extracts, antigen purified anti-TFIIIC $\beta$ antibodies (or preimmune antibodies as a negative control) were cross-linked to protein A-Sepharose 4B beads by dimethylpimelimidate. After extensive washing with $300 \mathrm{~mm}$ $\mathrm{KCl}$ (in $\mathrm{BC}$ buffer) the beads were incubated (1:1 ratio) with HeLa nuclear extract in a spin reaction column. The mixture was rotated at $4^{\circ} \mathrm{C}$ for $4 \mathrm{hr}$, and the depleted extract was separated from the protein $\mathrm{A}-$ Sepharose $4 \mathrm{~B}$ by centrifugation.

\section{Virus stock and infection}

Adenovirus was propagated and titered using techniques described previously (Hoeffler and Roeder 1985). Wild-type adenovirus type 2 was titered on HeLa monolayer cells and the Ad5 mutant dl312 (Gaynor and Berk 1983) was titered on 293 cells. Cells to be infected were concentrated 10-fold by centrifugation and resuspension in one-tenth volume serum-free media. Infection was for $1 \mathrm{hr}$ at a multiplicity of infection of 20 to 1 . Fresh medium with $5 \%$ serum was added after infection to original volume. Cells were harvested $6 \mathrm{hr}$ after infection for analysis and extract production.

\section{Extract preparation, general factor purification, and transcription assays}

Nuclear extract was prepared from HeLa cells (uninfected, infected with Ad2, infected with dl312, high serum, low serum) (Hoeffler et al. 1988) by the procedure of Dignam et al. (1983), except that the nuclear extraction was performed with $0.5 \mathrm{M}$ $\mathrm{KCl}$ rather than $0.42 \mathrm{M} \mathrm{KCl}$ in the extraction buffer. Transcriptions were performed as described previously (Kovelman and Roeder 1992). Templates used were covalently closed circular DNAs at concentrations of $2.5 \mathrm{mg} / \mathrm{ml}$ for all promoters [VAl promoter, pVA1; tRNA, ptRNA; 5S RNA, p5S (Lagna et al. 1994)]. For assays in the reconstituted system, RNA polymerase III was purified as described by Kovelman and Roeder (1992). TFIIIB (Mono Q fraction) and TFIIIC1 (Mono Q fraction) were purified as described by Chiang et al. (1993) except that TFIIIC1 was purified from $\mathrm{S} 100 \mathrm{P} 110.6 \mathrm{M} \mathrm{KCl}$ fraction.

\section{EMSA immunoblot assays}

The labeled adenovirus VAl gene probe encompassed a region (from -30 to +99 ) containing both the A block and the B block consensus sequence and was prepared as described (Hoeffler et al. 1988). Binding conditions were $8 \%$ glycerol (vol/vol), $3.5 \mathrm{mM}$ $\mathrm{MgCl}_{2}, 20 \mathrm{~mm}$ HEPES (pH 7.9), 1 mM DTT, 0.04 mM EDTA, 70 $\mathrm{mM} \mathrm{KCl}$, and $1-5 \mathrm{ng}$ of purified TFIIIC2a in a total reaction volume of $25 \mu \mathrm{l}$. After incubation at $30^{\circ} \mathrm{C}$ for $15 \mathrm{~min}$ the samples were loaded directly into $3.5 \%$ PAGE /acrylamide/bis-acrylamide $37.5: 1)$ in $0.25 \times$ TBE $(22 \mathrm{~mm}$ Tris, $22 \mathrm{~mm}$ boric acid, 0.6 mM Na${ }_{2}$ EDTA) and electrophoresed at $100 \mathrm{~V}$ for $5 \mathrm{hr}$ at $4^{\circ} \mathrm{C}$. Gels were dried and exposed to X-ray film.

Immunoblots were performed as described by the manufac- turer (ECL system, Amersham). Antigen-purified anti-TFIIIC $\beta$ antibodies had a protein concentration of $1.2 \mathrm{mg} / \mathrm{ml}$ and were typically used at 1:5000 dilution.

\section{Acknowledgments}

We thank Giorgio Lagna and Beth Moorefield for helpful discussions and critical readings of this paper. Oligonucleotide synthesis and protein sequence analysis were provided by the Rockefeller University Protein Sequencing Facility, which is supported in part by National Institutes of Health (NIH) shared instrumentation grants and by funds provided by the U.S. Army and Navy for purchase of equipment.

This work was supported by a grant (CA42567) from the NIH to R.G.R. and by general support from the Pew Trusts to the Rockefeller University. E.S. was supported by a grant from the Leslie Arps Cancer Research Fund and by an NIH Virology training grant (CA09673).

The publication costs of this article were defrayed in part by payment of page charges. This article must therefore be hereby marked "advertisement" in accordance with 18 USC section 1734 solely to indicate this fact.

\section{References}

Altschul, S.F., W. Gish, W. Miller, E.W. Myers, and D.J. Lipman. 1990. Basic local alignment search tool. I. Mol. Biol. 215: 403-410.

Bartholomew, B., G.A. Kassavetis, B.R. Braun, and E.P. Geiduschek. 1990. The subunit structure of Saccharomyces cerevisiae transcription factor IIIC probed with a novel photocrosslinking reagent. EMBO J. 9: 2197-2205.

Berk, A.J. 1986. Adenovirus promoters and E1A transactivation. Annu. Rev. Genet. 20: 45-79.

Berger, S.L. and W.R. Folk. 1985. Differential activation of RNA polymerase III-transcribed genes by the polyoma virus enhancer and adenovirus ElA gene products. Nucleic Acids Res. 13: 1413-1428.

Boguski, M.S., R.S. Sikorski, P. Hieter, and M. Goebl. 1990. Expanding family. Nature 346: 114.

Brow, D.A. and C. Guthrie. 1990. Transcription of a yeast U6 snRNA gene requires a polymerase III promoter element in a novel position. Genes \& Dev. 4: 1345-1356.

Burnol, A.-F., F. Margottin, J. Huet, G. Almouzni, M.-N. Prioleau, M. Mechali, and A. Sentenac. 1993. TFIIIC relieves repression of U6 snRNA transcription by chromatin. Nature 362: 475-477.

Chiang C., H. Ge, Z. Wang, A. Hoffmann, and R.G. Roeder. 1993. Unique TATA-binding protein-containing complexes and cofactors involved in transcription by RNA polymerases II and III. EMBO I. 12: 2749-2762.

Dean, N. and A.J. Berk. 1987. Separation of TFIIIC into two functional components by sequence specific DNA affinity chromatography. Nucleic Acids Res. 15: 9895-9907.

DeJong, J. and R.G. Roeder. 1993. A single cDNA, hTFIIA/a, encodes both the p35 and p19 subunits of human TFIIA. Genes \& Dev. 7: 2220-2234.

Dignam, J.D., R.M. Lebovitz, and R.G. Roeder. 1983. Accurate transcription initiation by polymerase II in a soluble extract from isolated mammalian nuclei. Nucleic Acids Res. 11: $1475-1489$.

Dynlacht, B.D., A.A. Weinzierl, and R. Tjian. 1993. The dTAF $_{\mathrm{II}} 80$ subunit of Drosophila TFIID contains $\beta$-transducin repeats. Nature 363: 176-179.

Fradkin, L.G., S.K. Yoshinaga, A.J. Berk, and A. Dasgupta. 1987. 
Inhibition of host cell RNA polymerase III-mediated transcription by poliovirus: Inactivation of specific transcription factors. Mol. Cell. Biol. 7: 3880-3887.

Gabrielsen, O.S., and A. Sentenac. 1991. RNA polymerase III (C) and its transcription factors. Trends Biol. Sci. 16: 412-416.

Gaynor. R.B. and A.J. Berk. 1983. Cis-acting induction of adenovirus transcription. Cell 33: 683-693.

Gaynor, R.B., L.T. Feldman, and A.J. Berk. 1985. Transcription of class III genes activated by viral immediate early proteins. Science 230: 447-450.

Geiduschek, E.P. and G.A. Kassavetis. 1992. RNA polymerase III transcription complexes. In Transcription regulation (ed. K. Yamamoto|, pp. 247-280. Cold Spring Harbor Laboratory Press. Cold Spring Harbor, New York.

Geiduschek, E.P. and G.P. Tocchini-Valentini. 1988. Transcription by RNA polymerase III. Annu. Rev. Biochem. 57: 873914.

Gilman, A.G. 1987. G proteins: Transducers of receptor-generated signals. Annu. Rev. Biochem. 56: 615-649.

Goebl, M. and M. Yanagida. 1991. The TPR snap helix: A novel protein repeat motif from mitosis to transcription. Trends Biol. Sci. 16: 173-177.

Harlow, E. and D. Lane. 1988. Antibodies: A laboratory manual. Cold Spring Harbor Laboratory, Cold Spring Harbor, New York.

Hemdan E.S., Y-J. Zhao, E. Sulkowski, and J. Porath. 1989. Surface topography of histidine residues: A facile probe by immobilized metal ion affinity chromatography. Proc. Natl. Acad. Sci. 86: 1811-1815.

Hernandez, N. 1993. TBP, a universal eukaryotic transcription factor? Genes \& Dev. 7: 1291-1308.

Hoeffler, W. K. and R.G. Roeder. 1985. Enhancement of RNA polymerase III transcription by the ElA gene product of adenovirus. Cell 41: 955-963.

Hoeffler, W.K., R. Kovelman, and R.G. Roeder. 1988. Activation of transcription factor IIIC by the adenovirus E1A protein. Cell 53: 907-920.

Ittmann, M., J. Ali, A. Greco, and C. Basilico. 1993. The gene complementing a temperature-sensitive cell cycle mutant of BHK cells is the human homologue of the yeast RPC53 gene, which encodes a subunit of RNA polymerase C (III). Cell Growth Differ. 4: 503-511.

Janknecht, R., G.D. Martynoff, J. Lou, R.A. Hipskind, A. Nordheim, and H.G. Stunnenberg. 1991. Rapid and efficient purification of native histidine tagged protein expressed by recombinant vaccinia virus. Proc. Natl. Acad. Sci. 88: 89728976.

Keleher, C.A., M.J. Redd, J. Schultz, M. Carlson, and A.D. Johnson. 1992. Ssn6-Tupl is a general repressor of transcription in yeast. Cell 68: 709-719.

Kokubo, T., D.-W. Gong, S. Yamashita, R.G. Roeder, M. Horikoshi, and Y. Nakatani. 1993. Molecular cloning, expression, and characterization of the Drosophila 85-kilodalton TFIID subunit. Mol. Cell. Biol. 13: 7859-7863.

Komachi, K., M.J. Redd, and A.D. Johnson. 1994. The WD repeats of Tupl interact with the homeo domain protein $\alpha 2$. Genes \& Dev. 8: 2857-2867.

Kovelman, R. and R.G. Roeder. 1990. Sarkosyl defines three intermediate steps in transcription initiation by RNA polymerase III: Application to stimulation of transcription by E1A. Genes \& Dev. 4: 646-659.

1992. Purification and Characterization of two forms of human transcription factor IIIC. J. Biol. Chem. 267: 2444624456.

L'Etoile, N.D., M.L. Fahnestock, Y. Shen, R. Adbersold, and A.J.
Berk. 1994. Human TFIIIC box B-binding subunit. Proc. Natl. Acad. Sci. 91: 1652-1656.

Lagna, G., R. Kovelman, J. Sukegawa, and R.G. Roeder. 1994. Cloning and characterization of an evolutionarily-divergent DNA-binding subunit of mammalian TFIIIC. Mol. Cell. Biol. 14: 3053-3064.

Lefebvre, O., C. Carles, C. Conesa, R.N. Swanson, F. Bouet, M. Riva, and A. Sentenac. 1992. TFC3: Gene encoding the B-block binding subunit of the yeast transcription factor IIIC. Proc. Nat1. Acad. Sci. 89: 10512-10516.

Marck, C., O. Lefebvre, C. Carles, M. Riva, N. Chaussivert, A. Ruet, and A. Sentenac. 1993. The TFIIIB-assembling subunit of yeast transcription factor TFIIIC has both tetratricopeptide repeats and basic helix-loop-helix motifs. Proc. Natl. Acad. Sci. 90: 4027-4031.

Meissner, W., R. Holland, R. Waldschmidt, and K.H. Seifart. 1993. Transcription factor IIA stimulates the expression of classical pol III-genes. Nucleic Acids Res. 21: 1013-1018.

Moenne, A., S. Camier, G. Anderson, F. Margottin, J. Beggs, and A. Sentenac. 1990. The U6 gene of Saccharomyces cerevisiae is transcribed by RNA polymerase C (III) in vivo and in vitro. EMBO T. 9: 271-277.

Parson, M.C., and P.A. Weil. 1992. Cloning of TFCl, the Saccharomyces cerevisiae gene encoding the $95-\mathrm{kDa}$ subunit of transcription factor TFIIIC. J. Biol. Chem. 5: 2894-2901.

Parvin, J.D., B.M. Shykind, R.E. Meyers, J. Kim, and P.A. Sharp. 1994. Multiple sets of basal factors initiate transcription by RNA polymerase II. J. Biol. Chem. 269: 18414-18421.

Pinto, I., D.E. Ware, and M. Hampsey. 1992. The yeast SUA7 gene encodes a homolog of human transcription factor TFIIB and is required for normal start site selection in vivo. Cell 68: $977-988$.

Segall, J., T. Matsui, and R.G. Roeder. 1980. Multiple factors are required for the accurate transcription of purified genes by RNA polymerase III. J. Biol. Chem. 255: 11986-11991.

Sollerbrant, K., G. Akusjarvi, and C. Svensson. 1993. Repression of RNA polymerase III transcription by adenovirus E1A. $/$. Virol. 67: 4195-4204.

Swanson, R.N., C. Conesa, O. Lefebvre, C. Carles, A. Ruet, E. Quemeneur, J. Gagnon, and A. Sentenac. 1991. Isolation of TFCl, a gene encoding one of two DNA-binding subunits of yeast transcription factor $\tau$ (TFIIIC). Proc. Natl. Acad. Sci. 88: 4887-4891.

Tzamarias, D., and K. Struhl. 1994. Functional dissection of the yeast Cyc8-Tup1 transcriptional co-repressor complex. $\mathrm{Na}$ ture 369: 758-761.

van der Voorn, L. and H.L. Ploegh. 1992. The WD-40 repeat. FEBS Lett. 307: 131-134.

Waldschmidt, R., I. Wanandi, and K.H. Seifart. 1991. Identification of transcription factors required for the expression of mammalian U6 genes in vitro. EMBO J. 10: 2595-2603.

Yoshinaga, S., N. Dean, M. Han, and A.J. Berk. 1986. Adenovirus stimulation of transcription by RNA polymerase III: Evidence for an E1A-dependent increase in transcription factor IIIC concentration. EMBO I. 5: 343-354.

Yoshinaga, S., P.A. Boulanger, and A.J. Berk. 1987. Resolution of human transcription factor TFIIIC into two functional components. Proc. Natl. Acad. Sci. 84: 3585-3589.

Yoshinaga, S.K., N.D. L'Etoile, and A.J. Berk. 1989. Purification and characterization of transcription factor IIIC2. J. Biol. Chem. 264: 10726-10731.

Young, R.A. 1991. RNA polymerase II. Annu. Rev. Biochem. 60: 689-715. 


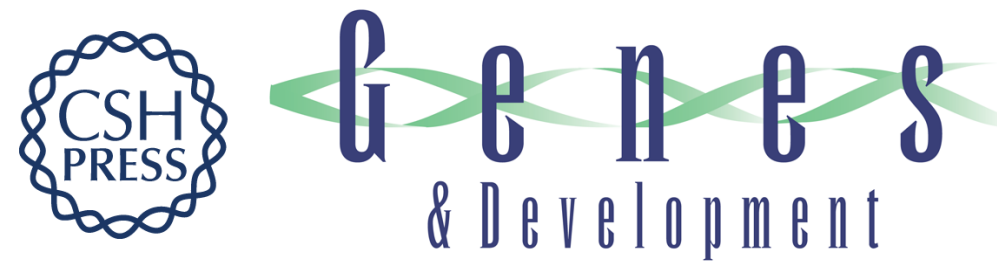

\section{Cloning and characterization of a TFIIIC2 subunit (TFIIIC beta) whose presence correlates with activation of RNA polymerase III-mediated transcription by adenovirus E1A expression and serum factors.}

E Sinn, Z Wang, R Kovelman, et al.

Genes Dev. 1995, 9:

Access the most recent version at doi:10.1101/gad.9.6.675

References This article cites 48 articles, 22 of which can be accessed free at: http://genesdev.cshlp.org/content/9/6/675.full.html\#ref-list-1

License

Email Alerting Receive free email alerts when new articles cite this article - sign up in the box at the top Service right corner of the article or click here.

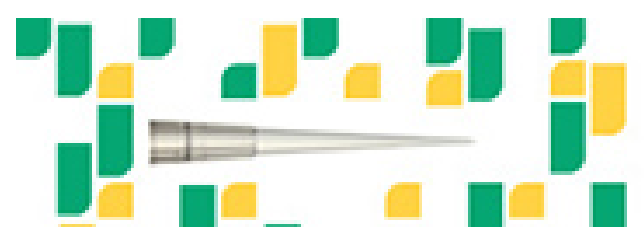

Focused on your science. 